\title{
Sulbactam pivoxil powder attributes and compatibility study with excipients
}

\author{
Loreana C. Gallo ${ }^{1,2}$, Noelia L. Gonzalez Vidal ${ }^{2,3}$, Fabio F. Ferreira ${ }^{4,5}$ and María V. Ramírez-Rigo ${ }^{1,2^{*}}$
}

\begin{abstract}
Background: Sulbactam pivoxil is an irreversible $\beta$-lactamase inhibitor that can be used with $\beta$-lactam antibiotics to improve antibacterial therapy by the oral route. Relevant properties of this drug for pharmaceutical manufacturing are not available in the open literature. In this work, a solid-state characterization of sulbactam pivoxil at the molecular, particle, and bulk levels was performed.

Results: Particles exhibited a mean diameter of about $350 \mu \mathrm{m}$, irregular shape crystals, and good flow properties. This work presents for the first time the crystal structure of this $\beta$-lactamase inhibitor obtained by X-ray diffraction analysis. Fourier-transform infrared results showed the characteristic bands of aliphatic hydrocarbons and ester groups. The differential scanning calorimetry curve exhibited a sharp endothermic peak at $109^{\circ} \mathrm{C}$ corresponding to sulbactam pivoxil melting. The thermogravimetric curve revealed a mass loss at $184^{\circ} \mathrm{C}$ associated with a decomposition process. This powder showed a moisture content of $0.34 \%$ and a water activity of 0.463 . Potential interactions between sulbactam pivoxil and common pharmaceutical excipients were evaluated by thermal analysis. The endothermic peak and the enthalpies of melting were preserved in almost all the analyzed mixtures.

Conclusion: The powder was constituted by micro-sized crystals of sulbactam pivoxil that had suitable physicochemical properties for processing in controlled humidity environments. Thermal analyses suggested that sulbactam pivoxil is compatible with most of the evaluated excipients. The information obtained in the present study is relevant for the development, manufacturing, and storage of formulations that include sulbactam pivoxil.
\end{abstract}

Keywords: $\beta$-lactamase inhibitor, Powder characterization, Thermal analysis, Compatibility

\section{Background}

Sulbactam is a $\beta$-lactamase inhibitor that has been used clinically to treat infections where the bacteria has developed resistance by the production of $\beta$-lactamase enzymes [1]. Considering the poor absorption in the gastrointestinal tract of this active pharmaceutical ingredient (API), the prodrug sulbactam pivoxil (SP) is preferred for oral formulations [2].

The combination amoxicillin (AM)/SP is widely used to improve the antibacterial therapy of upper respiratory

\footnotetext{
* Correspondence: vrrigo@plapiqui.edu.ar

'Planta Piloto de Ingeniería Química (PLAPIQUI), CONICET_Universidad Nacional del Sur (UNS), Camino La Carrindanga km 7, 8000 Bahía Blanca, Argentina

2Departamento de Biología, Bioquímica y Farmacia, UNS, Bahía Blanca, Argentina

Full list of author information is available at the end of the article
}

tract infections [3-5]. A clinical study has compared the efficacy of antimicrobial extemporaneous suspensions of AM containing two different $\beta$-lactamase inhibitors (SP and clavulanic acid) for children suffering from otitis media. The study concluded that both SP and clavulanic acid were equally clinically effective for this pathology [4]. However, SP exhibited higher chemical stability than clavulanic acid, which should be considered for the production and therapeutic use of combined oral formulations with AM [6].

This combination of APIs is widely used to treat pediatric infections in the form of extemporaneous suspensions [7]. This formulation consists of a solid phase (i.e., a powder manufactured and packaged for long-term storage), subsequently dispersed with water to form a suspension for patient use $[7,8]$. The powder is composed of 
APIs and excipients. In order to ensure dose uniformity, prevent microbial growth during storage and use, and promote chemical and physical stability [9], suitable diluents with adequate flowability, preservatives, and suspending/ dispersing agents should be included in the formulation [7]. Besides, organoleptic properties are of particular concern for drug administration in pediatrics, requiring excipients such as flavors and sweeteners, e.g., sucrose, the major component of this type of dosage form [7].

As can be seen, the correct selection of excipients is crucial in the pharmaceutical manufacturing of extemporaneous suspension, in order to assure safety and/or efficacy [10]. In this sense, the excipients' election in the pre-formulation stage is based on their functionality and compatibility with the API. Several techniques have been developed to evaluate drug-excipient interaction, including thermal methods such as differential scanning calorimetry (DSC). DSC presents several advantages, requires a small amount of sample, shows rapid results, and presents a straightforward detection of possible physical interactions $[11,12]$. This technique has been increasingly used for the quick assessment of physicochemical incompatibility between APIs and excipients, by comparing the thermograms of pure components and their 1:1 physical mixtures (PM). An appearance or disappearance of peaks, a significant shift in the melting point, and/or a variation in the relevant enthalpy values $(\Delta \mathrm{H})$ of the $\mathrm{PM}$, compared with starting materials, could indicate incompatibility. For this reason, these useful predictions of potential issues can help to exclude an excipient at an initial stage of product development [12].

Even though SP has been in use for several decades, its solid-state properties have not been extensively reported in the peer-reviewed literature. Only one work described a simple synthesis method of SP and focused on the characterization in terms of synthesis yield, melting point, and infrared and ${ }^{1} \mathrm{H}$ NMR spectra [3]. To the best of our knowledge, contributions to the SP's solid-state characterization, as a pure ingredient and in preformulation mixtures, have not been reported in the open literature. Based on the quality by design approach, the knowledge of raw material attributes is required to support product formulation and process development $[8,13,14]$.

In this context, this work aimed to characterize relevant properties of commercially available SP, in terms of particle morphology and size distribution, flowability, moisture content and water activity, infrared spectra, crystal structure, and thermal behavior. The characterization was complemented with fast screening compatibility studies using common excipients for extemporaneous suspensions to obtain meaningful information for the preformulation stage.

\section{Methods \\ Materials}

SP was obtained from Kalung Group Ltd. (Hong Kong, China). The evaluated excipients (listed in Table 1) were selected because they are commonly used to develop extemporaneous suspensions. Sucrose was obtained from Ledesma (Buenos Aires, Argentina), and the other excipients were acquired from Saporiti (Buenos Aires, Argentina). SP and the excipients were used as received from the suppliers. Potassium bromide ( $\mathrm{KBr}$, spectroscopic grade, Merck, Darmstadt, Germany) was used for infrared spectra determination.

\section{Methods}

\section{Particle size and morphology}

Particle size distribution was determined with a laser diffraction instrument (LA 950 V2, Horiba, Kyoto, Japan), equipped with a powder jet dry feeder system. The average diameter value was expressed as $D_{4,3}$. The diameters $D_{90}, D_{50}$, and $D_{10}$, which represent the diameters where $90 \%, 50 \%$, and $10 \%$ of the particle population lie below each diameter, were also reported. Measurements were performed in triplicate.

The particles' morphology was assessed using a transmitted light microscope with a polarizing filter over the light source (Karl Zeiss, Jena, Germany). Polarized light was used to distinguish between the crystalline material (birefringent areas) and the non-crystalline areas (dark regions).

\section{Flow properties}

The powder flow properties were evaluated in terms of the angle of repose $(\alpha)$ and Carr's compressibility index (CI). The angle of repose was determined by pouring $2 \mathrm{~g}$ of SP through a funnel located at a fixed height on a graph paper. The height $(\mathrm{h})$ and radius $(\mathrm{r})$ of the conical pile formed was measured $(n=10)$. The tangent of the angle of repose was calculated as the $\mathrm{h} / \mathrm{r}$ ratio [15].

For CI determination, $4 \mathrm{~g}$ of drug powder was poured into a $10-\mathrm{ml}$ graduated cylinder $(n=3)$. Bulk density $\left(D_{\mathrm{b}}\right)$ was calculated as the ratio of the sample's weight in the cylinder to the volume occupied by the bulk sample. Tap density $\left(D_{\mathrm{t}}\right)$ was estimated by tapping the cylinder until no measurable change in volume was noticed. CI was calculated following Eq. (1) [15].

$$
C I=\frac{D_{t}-D_{b}}{D_{t}} \times 100
$$

\section{Moisture content and water activity}

A moisture analyzer with halogen heating (model M45, OHAUS, Pine Brook, United States) was used for the determination of SP moisture content. About $500 \mathrm{mg}$ of 
Table 1 Excipients for extemporaneous suspensions

\begin{tabular}{lll}
\hline Excipient & Abbreviation & Function \\
\hline Aspartame & A & Sweetening agent \\
Carboxymethyl cellulose & CMC & Suspending agent \\
Carboxypolymethylene & CPM & Suspending agent \\
Citric acid & CA & Antioxidant—flavor enhancer \\
Strawberry essence & E & Flavoring agent \\
Mannitol & M & Diluent-sweetening agent \\
Methylcellulose & MC & Suspending agent \\
Microcrystalline cellulose PH200 & MCC-200 & Suspending agent \\
Microcrystalline cellulose PH102 & MCC-102 & Suspending agent \\
Sodium benzoate & SB & Antimicrobial preservative \\
Sodium methylparaben & SM & Antimicrobial preservative \\
Sodium saccharin & SS & Sweetening agent \\
Sucrose & S & Diluent-sweetening agent
\end{tabular}

the drug was heated at $60^{\circ} \mathrm{C}$ until the weight change was less than $1 \mathrm{mg}$ in $90 \mathrm{~s}$. The sample's water activity was measured at $25^{\circ} \mathrm{C}$ using a LabMaster Aw meter (Novasina, Pfäffikon, Switzerland).

\section{Fourier-transform infrared spectroscopy}

The FT-IR spectrum was obtained by diffuse reflectance infrared Fourier transform spectroscopy (DRIFTS, Nicolet 6700 FT-IR spectrometer, Thermo Scientific, Madison, USA). SP was blended with $\mathrm{KBr}$, and the FT-IR spectra (average scans $=64$, resolution $=4 \mathrm{~cm}^{-1}$ ) were recorded in the $4000.0-400.0 \mathrm{~cm}^{-1}$ range.

\section{$X$-ray powder diffraction}

X-ray powder diffraction data were collected on a STADI-P diffractometer (Stoe ${ }^{\oplus}$, Darmstadt, Germany) using $\mathrm{CuK} \alpha_{1}$ radiation $(\lambda=1.54056 \AA)$, selected by a curved $\mathrm{Ge}(111)$ monochromator, operating in transmission geometry at $40 \mathrm{kV}$ and $40 \mathrm{~mA}$. The sample was loaded between two acetate-cellulose foils $(0.014 \mathrm{~mm}$ thickness), and the X-ray photons were detected by a Mythen $1 \mathrm{~K}$ (Dectris ${ }^{\circ}$, Baden, Switzerland) silicon strip detector. Data were collected from $6.000^{\circ}$ to $94.185^{\circ}$ $(2 \theta)$, with step sizes of 0.015 and a counting time of 100 $\mathrm{s}$ at each $1.05^{\circ}$.

\section{Thermogravimetric analysis and differential scanning calorimetry}

Compatibility studies TGA analysis of SP was carried out in simultaneous DSC/TGA equipment (SDT Q600, New Castle, USA) by heating from 20 to $1000{ }^{\circ} \mathrm{C}$ at $10{ }^{\circ} \mathrm{C} / \mathrm{min}$, under a nitrogen atmosphere.

DSC analyses were conducted with the same equipment (SDT Q600, New Castle, USA) by heating from 20 to $500{ }^{\circ} \mathrm{C}$ at $10{ }^{\circ} \mathrm{C} / \mathrm{min}$, under a nitrogen atmosphere. PMs of SP and excipients were prepared for compatibility studies, by mixing equal quantities of the API and each excipient in a mortar at room temperature $\left(25^{\circ} \mathrm{C}\right)$. The 1:1 ratio $(\mathrm{w} / \mathrm{w})$ was selected to maximize the probability of detecting interactions. It is important to point out that the DSC analysis of sodium methylparaben (SM) and its PM were performed up to $170^{\circ} \mathrm{C}$ due to the boiling point of SM is between 190 and $280^{\circ} \mathrm{C}$.

The thermograms obtained for the pure SP and excipients were compared with those obtained from the corresponding PMs in order to detect any type of interaction. Thermogram evaluation was conducted using the Universal Analysis 2000 software (version 4.5A).

\section{Results}

\section{SP solid-state characterization}

The particle size distribution corresponded to a unimodal pattern, with characteristic diameters of $D_{10}, 176$ $\pm 23 ; D_{50}, 323 \pm 22 ; D_{90}, 533 \pm 11$; and $D_{4,3}, 343 \pm$ $17 \mu \mathrm{m}$ (Fig. 1). These values were in agreement with the particle sizes observed using optical microscopy (Fig. 2). Besides, the polarized light microphotograph showed that irregularly shaped crystals constitute the SP sample (Fig. 2).

Regarding SP flowability, the SP particles exhibited an angle of repose of $38.4 \pm 3.4^{\circ}$ and a CI value of $18.8 \pm$ $0.1 \%$. According to the United States Pharmacopeia [15], these results indicate that the SP powder exhibited a fair flow. The drug moisture content presented a low value of $0.34 \pm 0.02 \%$, and the measured Aw was 0.463 .

According to the FT-IR spectra, the drug molecule exhibited a peak at $2979.0 \mathrm{~cm}^{-1}$ assigned to aliphatic hydrocarbons, and bands at 1802.0-1757.0 and $1323.0 \mathrm{~cm}^{-1}$ corresponding to the ester group (Fig. 3). In addition, 


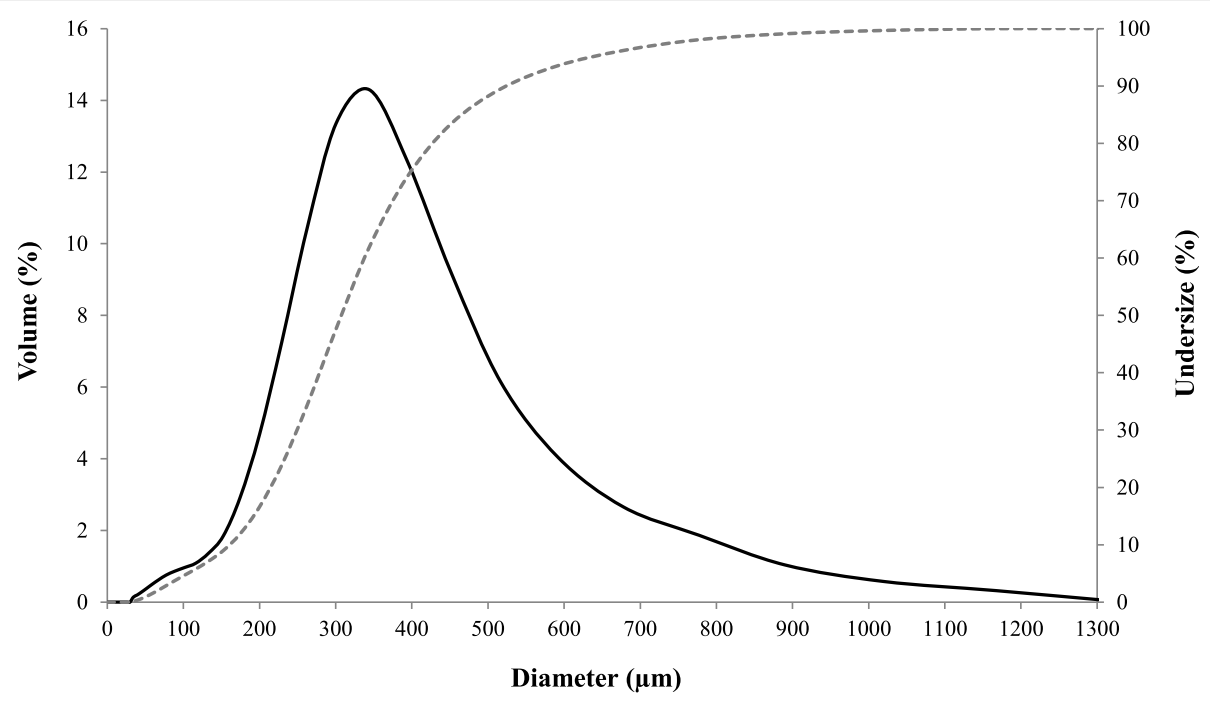

Fig. 1 Particle size distribution of SP

the X-ray pattern confirmed the crystalline nature of the SP (Fig. 4). Details about the crystal structure determination procedure can be found elsewhere [16-18]. Briefly, we selected the first 20 peaks to index the diffraction pattern using the TOPAS-Academic v7 software [19]. Systematic absences' analysis revealed the sample crystallized in a monoclinic crystal system (space group P21). MarvinSketch 20.20.0, 2020, ChemAxon (http:// www.chemaxon.com), was used to draw a 3D model of the sulbactam pivoxil chemical structure, which was then used as an input in the DASH software [20] to solve the crystal structure. The best solution was then used to perform the final Rietveld refinement, whose parameters are displayed in Table 2. Mercury (2020.2.0) was used to produce the crystal structure packing, atom numbering, and hydrogen bond interactions [21].

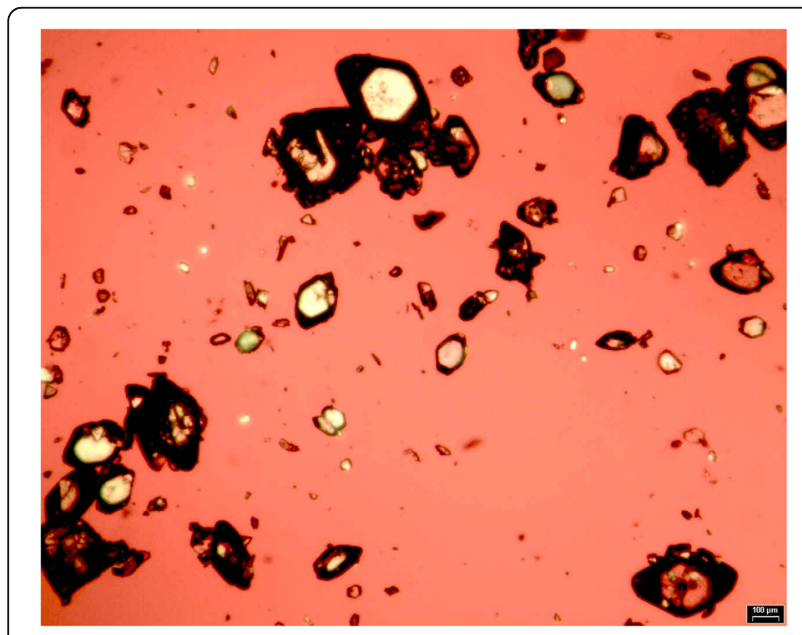

Fig. 2 Morphology of SP crystals
The thermal analyses showed that SP's heat flow curve presents a sharp endothermic event, with a maximum at $108.7^{\circ} \mathrm{C}$, indicating the melting process (Fig. 5a). Thermal decomposition of SP in a nitrogen atmosphere occurred in one event, in a range between 170.0 and $400.0^{\circ} \mathrm{C}$, with a maximum peak at $183.6^{\circ} \mathrm{C}$ and a mass loss of $73.27 \%$ (Fig. 5a).

\section{SP-excipients compatibility study}

Binary mixtures of SP with excipients were analyzed, and the obtained thermo-analytical results are presented in Table 3. It can be observed that no significant changes were recorded for onset temperature, peak temperature, and $\Delta H$ values for SP in the evaluated PMs, except for the physical mixture SP:SM. The thermal curves of the assayed binary mixtures, except SP:SM, can be considered a rough superposition of the curves of the SP and the excipients, evidencing the absence of incompatibility between them. An example of compatibility (SP:MCC102) can be seen in Fig. 5b, where the melting and decomposition peaks of SP were preserved in the PM. On the other hand, an interaction was suspected between SP and SM, because shifts of SP and SM endothermic peaks were observed in the PM (Fig. 5c). This is also confirmed by a significant decrease in the $\Delta H$ value for the SP melting peak in the PM, as shown in Table 3.

\section{Discussion}

The particles' morphology, density, and size constituted the main characteristics influencing the rheological behavior and packing efficiency of a powder. Several relations between these particles' characteristics and their rheological performance have been determined, such as a broader particle size distribution increases the packing 

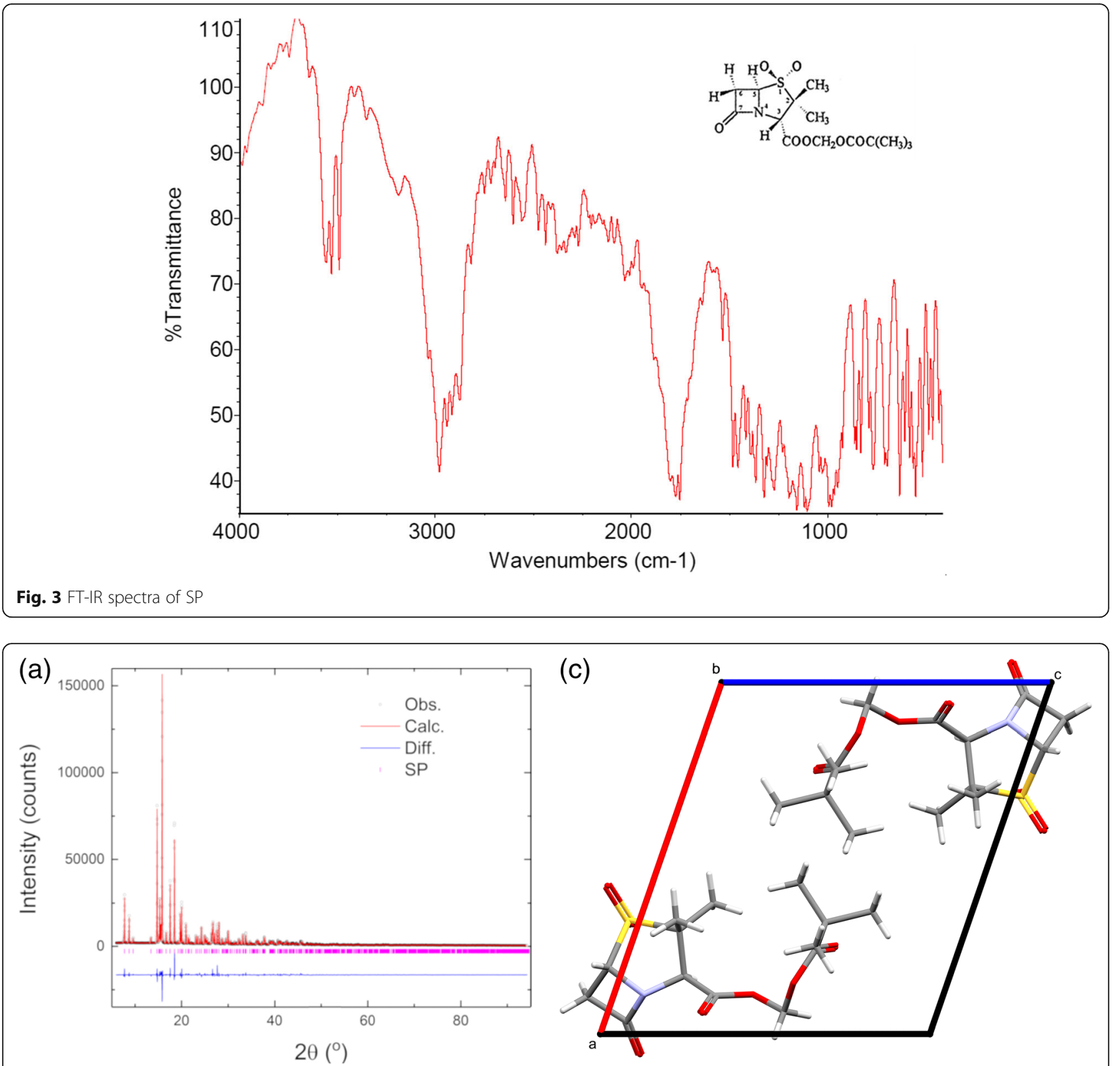

(b)
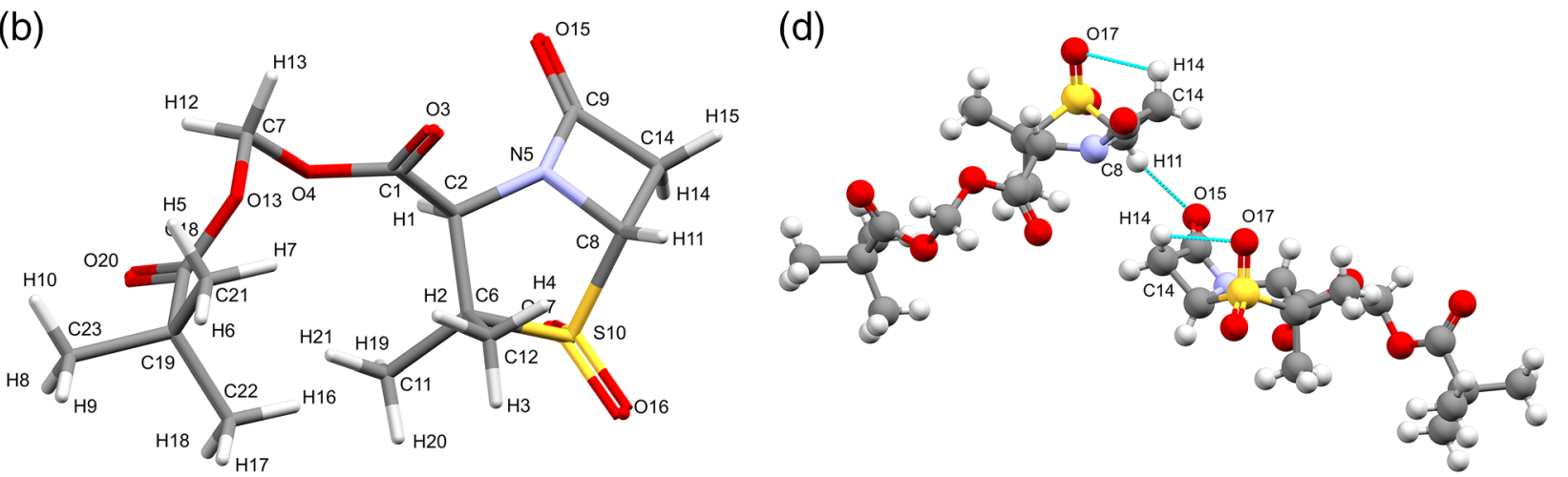

Fig. 4 a Rietveld plot of SP. The black circles represent the observed data while the red curve indicates the calculated pattern. The blue line at the bottom stands for the difference between the observed and calculated data. The vertical bars (magenta) represent the Bragg reflections. $\mathbf{b}$ Asymmetric unit displaying the atoms labeling. $\mathbf{c}$ Unit cell packing. d Intra and intermolecular hydrogen bonds (cyan lines) 
Table 2 Details from the Rietveld refinement of the crystal structure of SP

\begin{tabular}{|c|c|}
\hline Chemical formula & $\mathrm{C}_{14} \mathrm{H}_{21} \mathrm{NO}_{7} \mathrm{~S}$ \\
\hline Formula weight $\left(\mathrm{g} \mathrm{mol}^{-1}\right)$ & 347.38 \\
\hline Crystal system & Monoclinic \\
\hline Space group & $P 2_{1}($ Nr. 4) \\
\hline$a, b, c(\AA)$ & $12.0644(5) ; 7.0549(3) ; 10.7004(4)$ \\
\hline$\beta\left(^{\circ}\right)$ & $109.0602(19)$ \\
\hline Volume $\left(\AA^{3}\right)$ & $860.81(7)$ \\
\hline$Z, Z^{\prime}$ & 2,1 \\
\hline$\rho_{\text {calc }}\left(\mathrm{g} \mathrm{cm}^{-3}\right)$ & $1.3402(1)$ \\
\hline $\mathrm{T}(\mathrm{K})$ & $298(2)$ \\
\hline \multicolumn{2}{|l|}{ Data collection } \\
\hline Diffractometer & STADI P \\
\hline Monochromator & Ge(111) \\
\hline Wavelength $(\AA)$ & 1.54056 \\
\hline $2 \theta$ range $\left(^{\circ}\right)$ & $6.000-94.185$ \\
\hline Step size $\left({ }^{\circ}\right)$ & 1.05 \\
\hline Time per step (s) & 100 \\
\hline \multicolumn{2}{|l|}{ Refinement } \\
\hline Number of data points & 5580 \\
\hline Number of contributing reflections & 875 \\
\hline Number of restraints & 85 \\
\hline Number of refined parameters & 152 \\
\hline$R_{p}(\%)$ & 5.367 \\
\hline$R_{\exp }(\%)$ & 2.560 \\
\hline$R_{w p}(\%)$ & 6.831 \\
\hline$R_{\text {Bragg }}(\%)$ & 3.069 \\
\hline$x^{2}$ & 2.668 \\
\hline
\end{tabular}

density but decreases the powder flowability; coarse particles have better flowability than their fine counterparts; spherical particles simultaneously improve both the powder flowability and the packing efficiency [22]. In this context, SP powder presented a fair flow, which is in good agreement with the irregular shape of its particles (Fig. 2). Therefore, SP powder flowability could allow acceptable manipulation during pharmaceutical manufacturing.

The Aw parameter represents the relative equilibrium humidity of the drug [23]. The equilibrium relative humidity could be defined as the relative humidity at which a product neither gains moisture nor dries out and could be obtained by multiplying the water activity by 100 [24]. Therefore, SP can absorb moisture at an ambient relative humidity $(\mathrm{RH})$ higher than $46 \%$. Besides, water activity is a good indicator of microbiological stability, since no microorganism (neither bacteria, molds, nor yeasts) can grow at Aw values lower than 0.60 [24]. In this sense, the obtained result could indicate proper conditions of SP for storage without microbiological contamination concerns. It is important to highlight that knowledge of this parameter is essential to determine the ambient conditions for properly processing and conserving SP [25].

The FT-IR spectra showed the typical chemical structure reported for SP, which was in good agreement with the results obtained by Changov et al. [3]. Besides, this work presents for the first time the crystal structure of this $\beta$-lactamase inhibitor. By using a simulated annealing approach, the crystal structure was solved. It is important to highlight that X-ray powder diffraction data were used to index the pattern (please see Table 2, CCDC Number 1921588). Considering that the diffraction pattern of each API crystalline form is unique, this information can also be used for SP identification. Moreover, this supramolecular quality attribute can be useful to study potential SP phase transformations induced by the processing or storage of fixed-dose combination products (tablets, capsules, and powders for suspensions) [26].

The possible interactions between the API and the excipients are deduced from the DSC curves by the appearance, shift, or disappearance of peaks, especially the melting peak and/or variations in $\Delta H$ values. Modifications in the peak shape and/or peak onset may indicate an interaction, although some broadening of the peaks or small variation in the enthalpies could result from the lower purity of each component in the PM or the content uniformity of the analyzed blends, respectively [27]. The melting endotherm was preserved in all the analyzed mixtures without significant alterations. The enthalpy values were reduced by half compared to the pure $\mathrm{SP}$, in almost all the samples, which corresponds to a typical behavior [27]. In the case of the combination of SP with SM, the variation in the enthalpy of fusion was highly significant compared to the individual components' thermograms, besides the recorded shifts of endothermic peaks. The thermograms suggested that SP is compatible with almost all the evaluated excipients, except SM. Therefore, the preservative agent could be replaced by sodium benzoate (SB), which conserved the melting peak and enthalpy values (Table 3). Complementary stability studies are needed to confirm the predicted incompatibility [28].

\section{Conclusion}

The analyzed material was clearly identified as SP by FT-IR. This substance is a crystalline solid, with irregularly shaped particles and a unimodal particle-size distribution, with a mean diameter of about $350 \mu \mathrm{m}$. The flow properties were suitable for processing in controlled humidity environments (less than $46 \% \mathrm{RH}$ ). The thermal analyses showed a melting point at $108.7^{\circ} \mathrm{C}$ and a thermal decomposition event at $183.6{ }^{\circ} \mathrm{C}$. According to the 
a)

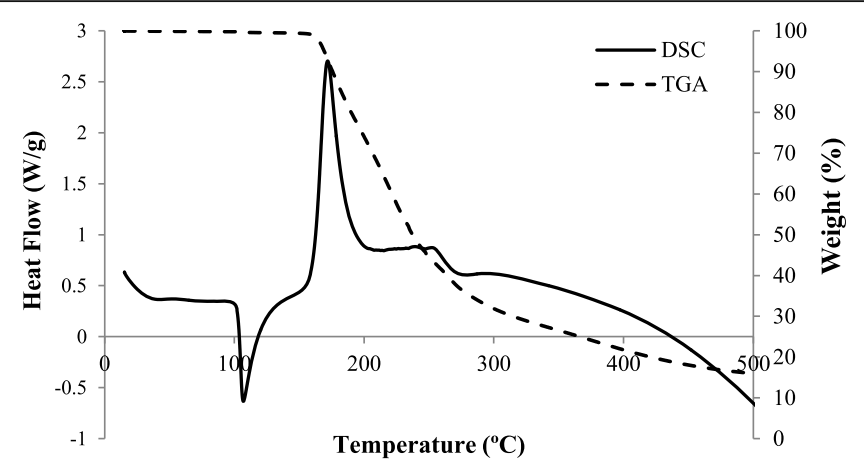

b)

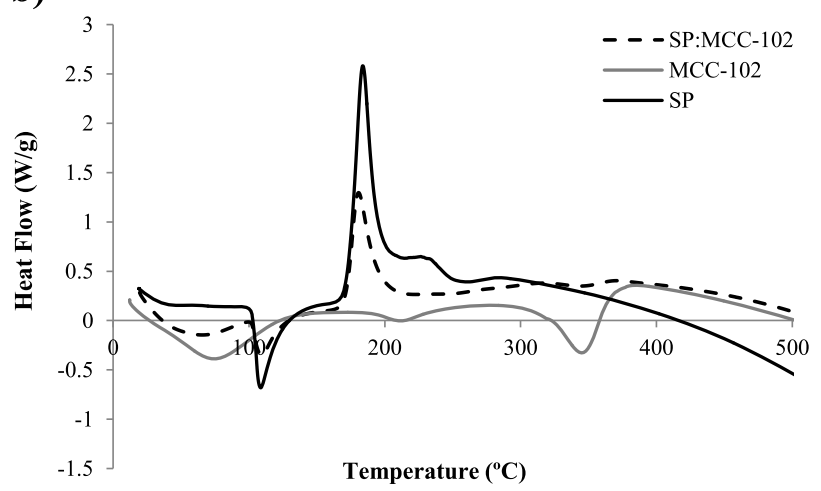

c)

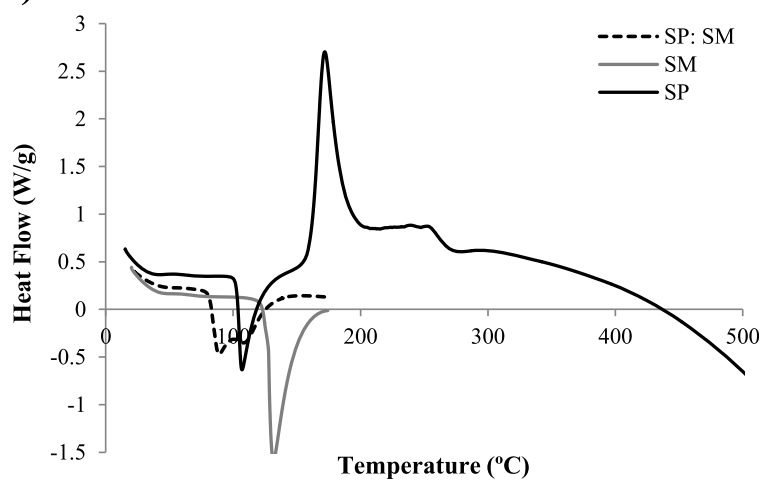

Fig. 5 Thermal analysis of SP, MCC-102, SM, and physical mixtures: a TGA and DSC curves of SP, b DSC thermograms of SP:MCC-102 (1:1) physical mixture and the pure materials, $\mathbf{c}$ DSC curves of SP:SM (1:1) physical mixture and the pure materials

Table 3 DSC thermoanalytical results for SP and binary mixtures with selected excipients

\begin{tabular}{llll}
\hline Sample & $\boldsymbol{T}_{\text {onset }}\left({ }^{\circ} \mathbf{C}\right)^{\mathbf{a}}$ & $\boldsymbol{T}_{\text {peak }}\left({ }^{\circ} \mathbf{C}\right)^{\mathbf{a}}$ & $\Delta \boldsymbol{H}_{\text {fus }}\left(\mathbf{J ~ g}^{-\mathbf{1}}\right)^{\mathbf{a}, \mathbf{b}}$ \\
\hline SP & 102.8 & 108.7 & 73.7 \\
SP:A & 101.2 & 110.1 & 37.5 \\
SP:CMC & 102.8 & 110.0 & 40.8 \\
SP:CPM & 101.1 & 109.8 & 38.1 \\
SP:CA & 100.1 & 107.9 & 39.3 \\
SP:E & 100.9 & 108.6 & 36.0 \\
SP:M & 101.7 & 108.2 & 38.4 \\
SP:MC & 100.7 & 109.3 & 33.7 \\
SP:MCC-102 & 101.6 & 109.5 & 37.5 \\
SP:MCC-200 & 100.9 & 109.0 & 38.0 \\
SP:SB & 101.4 & 107.4 & 34.4 \\
SP:SM & 101.2 & 109.9 & 7.7 \\
SP:SS & 100.6 & 109.8 & 39.4 \\
SP:S & 101.7 & 108.7 & 34.2 \\
\hline
\end{tabular}

${ }^{\mathrm{a}}$ The reported results corresponded to the melting peak of SP

${ }^{\mathrm{b}}$ Enthalpy of fusion $\left(\boldsymbol{\Delta} H_{\text {fus }}\right)$ is expressed as a function of the total sample mass calorimetry studies, SP did not show evidence of interaction with most of the evaluated excipients, excluding the preservative SM. The information obtained in the present work is relevant for the pharmaceutical manufacturing and storage of SP and the successful development of formulations that include this $\beta$-lactamase inhibitor.

\section{Abbreviations}

AM: Amoxicillin; API: Active pharmaceutical ingredient; Aw: Water activity; Cl: Carr's compressibility index; DSC: Differential scanning calorimetry; FTIR: Fourier-transform infrared spectroscopy; MC: Moisture content; PM: Physical mixtures; RH: Relative humidity; SP: Sulbactam pivoxil; XRD: X-ray powder diffraction

\section{Acknowledgements}

The authors kindly thank Fernanda Cabrera (PLAPIQUI), Mónica Murrie (Ministerio de Salud de la Provincia de Buenos Aires, Argentina), Rodolfo Salomon (CIC-UNS), and Subsecretaría de Vinculación Tecnológica (UNS) for their technical assistance.

\section{Authors' contributions}

LCG and NLGV contributed equally to the experimental data acquisition and interpretation. FFF performed the powder X-ray study. MVRR conceived of the presented idea and designed the plan of work. All the authors analyzed the data and interpreted the results. NLGV drafted the manuscript with the LCG and MVRR collaboration. All authors gave their individual critical revision and final approval of the summited document. 


\section{Funding}

Financial support was received from Secretaría de Políticas Universitarias (Ministerio de Educación, Argentina) (Res. SPU 1793/14), UNS (grant PGI 24/ B252, Argentina), and Conselho Nacional de Desenvolvimento Científico e Tecnológico (CNPq, Brazil) (grant 307664/2015-5).

\section{Availability of data and materials}

All data and material are available upon request.

\section{Ethics approval and consent to participate}

Not applicable.

\section{Consent for publication}

Not applicable.

\section{Competing interests}

The authors declare that they have no competing interests.

\section{Author details}

${ }^{1}$ Planta Piloto de Ingeniería Química (PLAPIQUI), CONICET_Universidad Nacional del Sur (UNS), Camino La Carrindanga km 7, 8000 Bahía Blanca, Argentina. ²Departamento de Biología, Bioquímica y Farmacia, UNS, Bahía Blanca, Argentina. ${ }^{3}$ CCT-Bahía Blanca, CONICET, Bahía Blanca, Argentina. ${ }^{4}$ Centro de Ciências Naturais e Humanas $(\mathrm{CCNH})$, Universidade Federal do ABC (UFABC), Santo André, SP, Brazil. ${ }^{5}$ Núcleo de Nanomedicina (NANOMED), Universidade Federal do ABC (UFABC), Santo André, SP, Brazil.

Received: 5 October 2020 Accepted: 29 December 2020

Published online: 20 January 2021

\section{References}

1. Drawz SM, Bonomo RA (2010) Three decades of $\beta$-lactamase inhibitors. Clin Microbiol Rev 23(1):160-201

2. English AR, Girard D, Jasys VJ, Martingano RJ, Kellogg MS (1990) Orally effective acid prodrugs of the $\beta$-lactamase inhibitor sulbactam. J Med Chem 33(1):344-347

3. Changov LS, Vassileva BK, Confino MN, Agapova NN (2000) An efficient method for the synthesis of sulbactam pivoxil. Farm 55:134-135

4. Casellas JM, Israele V, Marín M, Ishida MT, Heguilen R, Soutric J et al (2005) Amoxicillin-sulbactam versus amoxicillin-clavulanic acid for the treatment of non-recurrent-acute otitis media in Argentinean children. Int J Pediatr Otorhinolaryngol 69(9):1225-1233

5. Pei Q, Yang GP, Li ZJ, Peng XD, Fan JH, Liu ZQ (2011) Simultaneous analysis of amoxicillin and sulbactam in human plasma by HPLC-DAD for assessment of bioequivalence. J Chromatogr B Anal Technol Biomed Life Sci 879(21):2000-2004

6. Wildfeuer A, Räder K (1996) Stability of $\beta$-lactamase inhibitors and $\beta$-lactam antibiotics in parenteral dosage forms and in body fluids and tissue homogenates: a comparative study of sulbactam, clavulanic acid, ampicillin and amoxycillin. Int J Antimicrob Agents 6(SUPPL.1):S31-S34

7. Strickley RG, Iwata Q, Wu S, Dahl TC (2008) Pediatric drugs-a review of commercially available oral formulations. J Pharm Sci 97(5):1731-1774

8. Sonawane D, Chaudhari P, Thorat V, Dhavale S (2020) Quality by design approach for development of azithromycin oral reconstitutable suspension and its comparison with marketed product. EJPMR 7(2):431-440 Available via: https://www.ejpmr.com/admin/assets/downloads/1580465910.pdf. Accessed 20 June 2020

9. Standing JF, Tuleu C (2005) Paediatric formulations - getting to the heart of the problem. Int J Pharm 300(1-2):56-66

10. Verma RK, Garg S (2005) Selection of excipients for extended release formulations of glipizide through drug-excipient compatibility testing. J Pharm Biomed Anal 38(4):633-644

11. Pani NR, Nath LK, Acharya S (2011) Compatibility studies of nateglinide with excipients in immediate release tablets. Acta Pharm 61(2):237-247

12. Chadha R, Bhandari S (2014) Drug-excipient compatibility screening-role of thermoanalytical and spectroscopic techniques. J Pharm Biomed Anal 87: 82-97

13. Wang T, Alston KM, Wassgren CR, Mockus L, Catlin AC, Sudheera RF, Sumudinie F, Basu PK, Hoag SW (2013) The creation of an excipient properties database to support quality by design $(\mathrm{QbD})$ formulation development. Am Pharm Rev 16(4):16-25
14. Mohammed AQ, Sunkari PK, Srinivas P, Roy AK (2015) Quality by design in action 1: controlling critical quality attributes of an active pharmaceutical ingredient. Org Process Res Dev 19:1634-1644

15. United States Pharmacopeia and National Formulary (USP 41-NF36) (2018) The United States Pharmacopeial Convention. United States Pharmacopeia and National Formulary, Rockville

16. Ferreira FF, Trindade AC, Antonio SG, De Oliveira Paiva-Santos C (2011) Crystal structure of propylthiouracil determined using high-resolution synchrotron X-ray powder diffraction. Cryst Eng Comm 13(17):5474-5479

17. Sato JAP, Costa FN, Da Rocha MD, Barreiro EJ, Fraga CAM, Punzo F et al (2015) Structural characterization of LASSBio-1289: a new vasoactive Nmethyl-N-acylhydrazone derivative. Cryst Eng Comm 17(1):165-173

18. De Araujo GLB, Ferreira FF, Bernardes CES, Sato JAP, Gil OM, De Faria DLA et al (2018) A new thermodynamically favored flubendazole/maleic acid binary crystal form: structure, energetics, and in silico PBPK model-based investigation. Cryst Growth Des 18(4):2377-2386

19. Coelho AA (2018) TOPAS and TOPAS-academic: an optimization program integrating computer algebra and crystallographic objects written in $\mathrm{C}++$. J Appl Cryst 51(1):210-218

20. David WIF, Shankland K, van de Streek J, Pidcock E, Motherwell WDS, Cole JC (2006) ASH: a program for crystal structure determination from powder diffraction data. J Appl Cryst 39(6):910-915

21. Macrae CF, Sovago I, Cottrell SJ, Galek PTA, McCabe P, Pidcock E, Platings M, Shields GP, Stevens JS, Towler M, Wood PA (2020) Mercury 4.0: from visualization to analysis, design and prediction. J Appl Cryst 53:226-235

22. Brika SE, Letenneur M, Dion CA, Brailovski V (2020) Influence of particle morphology and size distribution on the powder flowability and laser powder bed fusion manufacturability of Ti-6Al-4 V alloy. Addit Manuf 31: 100929

23. Lutovska M, Mitrevski V, Geramitcioski T, Mijakovski V, Andreevski I (2016) Water activity vs. equilibrium moisture content Vodena Aktivnost Nasuprot Ravnotežne. J Proccess Energy Agric 4487(2):69-72 Available via: https:// scindeks-clanci.ceon.rs/data/pdf/1821-4487/2016/1821-44871602069L.pdf. Accessed 15 Jan 2020

24. Hartel RW, von Elbe JH, Hofberger R (2018) Water. In: Confectionery science and technology. Springer, Cham, pp 69-83

25. Yoshioka S, Stella VJ (2002) Stability of drugs and dosage forms. Kluwer Academic Publishers, United States

26. Thakral NK, Zanon RL, Kelly RC, Thakral S (2018) Applications of powder Xray diffraction in small molecule pharmaceuticals: achievements and aspirations. J Pharm Sci 107(12):2969-2982

27. Tița B, Fuliaş A, Bandur G, Marian E, Tița D (2011) Compatibility study between ketoprofen and pharmaceutical excipients used in solid dosage forms. J Pharm Biomed Anal 56(2):221-227

28. Chaves LL, Rolim LA, Gonçalves MLCM, Vieira ACC, Alves LDS, Soares MFR et al (2013) Study of stability and drug-excipient compatibility of diethylcarbamazine citrate. J Therm Anal Calorim 111(3):2179-2186

\section{Publisher's Note}

Springer Nature remains neutral with regard to jurisdictional claims in published maps and institutional affiliations.

\section{Submit your manuscript to a SpringerOpen ${ }^{\circ}$ journal and benefit from:}

- Convenient online submission

- Rigorous peer review

- Open access: articles freely available online

- High visibility within the field

- Retaining the copyright to your article

Submit your next manuscript at $>$ springeropen.com 